\title{
Epidemiology of systemic lupus erythematosus
}

\author{
Neil Hopkinson
}

It is perhaps surprising that despite numerous studies on the epidemiology of systemic lupus erythematosus (SLE) from around the world, there have been, until recently, no definitive studies on its occurrence in the United Kingdom. One study ${ }^{1}$ did estimate the prevalence of SLE in the United Kingdom, but this was a rough figure based on morbidity statistics from a selected number of general practices. The development of SLE is likely to depend on susceptibility genes and environmental factors, and epidemiological studies have much to offer in giving an insight into their interaction.

The pioneering work of Siegel and Lee focused on the occurrence of SLE in a confined part of New York City. ${ }^{2}$ The study predated the preliminary American Rheumatism Association (ARA) criteria, so the diagnostic criteria used were based on evidence of multisystem disease in three or more organ systems plus one characteristic laboratory finding. An annual incidence of $2 \cdot 0 / 100000$ population and a point prevalence of $14 \cdot 6 / 100000$ were observed. Ninety per cent of cases were women and black subjects were particularly affected. In Rochester, Minnesota, where $99 \%$ of the population are white, much higher occurrence rates were seen. ${ }^{3}$ An overall prevalence for SLE in 1968 of $48 / 100000$ and an incidence rate of 5.7/100 000 were attributed to better determination methods, as similar diagnostic criteria were used. When Michet $e t a l^{4}$ reassessed the occurrence of SLE in Rochester using the revised ARA classification criteria, ${ }^{5}$ a lower incidence rate was found but an equally high prevalence was confirmed $(40 \cdot 0 / 100000)$. High occurrence rates were also reported by Fessel in San Francisco (incidence $7 \cdot 6 / 100$ 000/year; prevalence $50 \cdot 8 / 100000$ ) but the ratio of black to white patients was similar to that of New York. ${ }^{6}$

The increased occurrence in black subjects is also seen in Jamaica, though accurate figures are not available. ${ }^{7}$ Studies in Africa, however, suggest that SLE is rare in black subjects. ${ }^{89} \mathrm{~A}$ study from Johannesburg not only showed a lower incidence of SLE in black compared with white subjects, but a considerably higher incidence in Asian Indians. ${ }^{10}$ Clearly there is not likely to be genetic homogeneity between black subjects living in different parts of the world but the data nevertheless suggest an environmental influence in the development of SLE. Similarly, environmental influences may help to explain the different prevalence of SLE in Chinese groups living in different parts of the world. For example, in Malaysia SLE is particularly common in Chinese subjects compared with the native Malay population. ${ }^{11}$ In Singa- pore $^{12}$ and in China ${ }^{13}$ itself SLE appears to be common among Chinese subjects, but in San Francisco the occurrence of SLE is not increased-that is, the proportion of Chinese patients with SLE is the same as the proportion of Chinese subjects in the general population. ${ }^{6}$

Epidemiological studies from Europe have used thorough retrieval methods to optimise determination rates. In Sweden, ${ }^{14}$ an overall annual incidence rate for adults (age $\geqslant 15$ years, four or more revised ARA criteria ${ }^{5}$ ) of $4.5 / 100000$ is reported with a point prevalence rate of $36 \cdot 3 / 100000$. Similarly a nationwide epidemiological study in Iceland reported an overall incidence of $3 \cdot 3 / 100000 /$ year with a point prevalence of $35 \cdot 9 / 100000 .^{15}$ These two sets of figures are substantially lower than the rates for the USA.

In Leicester, United Kingdom, the overall prevalence of SLE in white subjects is estimated to be $20 / 100000$ compared with a prevalence rate in Asian subjects of $40 / 100000 ; 16$ incidence rates are not available. Overall (white and Asian) prevalence rates for SLE in Leicester are approximately $26 \cdot 1 / 100000$ population based on reported population figures. ${ }^{17}$ This prevalence is lower than that seen in either Sweden or Iceland. A comprehensive study of the occurrence of SLE in Nottingham ${ }^{18}$ reported an overall incidence rate of SLE of $4 \cdot 0 / 100000 /$ year, with a one year period prevalence of $24 \cdot 6 / 100000 /$ year. The table summarises incidence and prevalence rates of SLE from the USA, Sweden, and the United Kingdom.

How can the different incidence and prevalence rates in the USA, in Sweden and Iceland, and in the United Kingdom be interpreted? Studies in Sweden and Iceland have shown increasing occurrence rates for SLE in the 1980s compared with previous studies in the 1960s and early 1970s. ${ }^{14} 15$ Therefore there is

Summary of reported incidence and prevalence rates of systemic lupus erythematosus in the USA, Sweden, and the United Kingdom

\begin{tabular}{lll}
\hline Area studied & $\begin{array}{l}\text { Incidence rate } \\
(/ 100 \text { 000/year })\end{array}$ & $\begin{array}{l}\text { Prevalence rate } \\
(/ 100 \text { 000 })\end{array}$ \\
\hline $\begin{array}{l}\text { New York City } \\
\text { 1956-65 }\end{array}$ & $2 \cdot 0$ & $14 \cdot 6$ \\
$\begin{array}{l}\text { Rochester } \\
\text { 1960-8 }\end{array}$ & $5 \cdot 7$ & $48 \cdot 0$ \\
$\begin{array}{l}\text { Rochester } \\
\text { 1950-79 }\end{array}$ & $1 \cdot 8$ & $40 \cdot 0$ \\
$\begin{array}{l}\text { San Francisco } \\
\text { 1965-73 }\end{array}$ & $7 \cdot 6$ & $51 \cdot 0$ \\
$\begin{array}{l}\text { Sweden } \\
\text { 1981-2 }\end{array}$ & $4 \cdot 5$ & 36.3 \\
$\begin{array}{l}\text { Nottingham } \\
\text { 1989-90 }\end{array}$ & $4 \cdot 0$ & $24 \cdot 6^{*}$
\end{tabular}

${ }^{*}$ One year period prevalence rate. 
no reason to think that occurrence rates of SLE in the USA have decreased since the time the previously high incidence and prevalence rates were reported. Furthermore, survival rates for SLE have improved from approximately $82 \%$ in 1971 (four year survival), ${ }^{20}$ to $91 \%$ in $1975,{ }^{21}$ and to $94 \%$ in $1986,{ }^{22}$ suggesting that prevalence rates in the USA will have increased. The higher rates in San Francisco could be explained by the high number of black subjects ( $9 \%$ of the population, $30 \%$ of patients with SLE), but this would not account for the high rates seen in Rochester. Thus it is possible that the occurrence rates of SLE in the USA are genuinely higher than those in Europe, though only a current epidemiological study in the USA will confirm this. What of the discrepancy in the occurrence of SLE seen in Iceland and Sweden compared with the UK? Incidence rates in the two groups seem similar but prevalence rates are considerably higher in Sweden and Iceland. Case retrieval is likely to be high in both areas and it is therefore likely that other factors account for the difference. Firstly, mortality rates may be different, perhaps due to differing racial and socioeconomic factors, or even in the quality of patient care. Secondly, in Sweden, ${ }^{23}$ differing selection criteria may have been used, leading to an unduly low number of incident cases. ${ }^{24}$ If incident rates in Sweden are really higher than in Leicester and Nottingham, using comparable selection criteria, it suggests that SLE is more common in Sweden than in the UK. In consideration of another autoimmune disease, insulin dependent diabetes mellitus, it is notable that Scandinavian countries have the highest documented incidence in the world. ${ }^{25}$ Furthermore, the rising incidence of insulin dependent diabetes mellitus in Europe over the last decade suggests that environmental factors may be responsible. Another interesting factor is the northerly latitude of Sweden compared with the United Kingdom; the prevalence of multiple

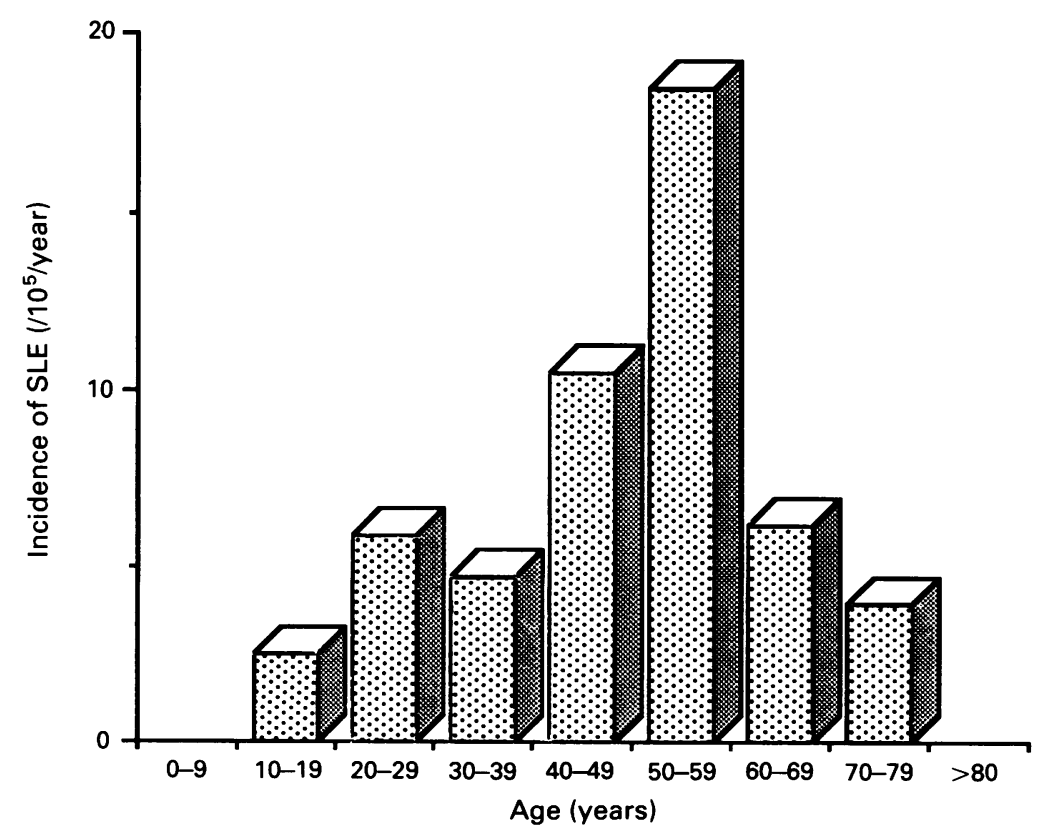

Specific incidence of systemic lupus erythematosus in women in Nottingham, United Kingdom, 1989-90. sclerosis, a disease also likely to be due to genetic and environmental influences, increases in prevalence from the south to the north of the United Kingdom, roughly in parallel with the increasing occurrence of HLA-DR2 in the population. ${ }^{26}$ Epidemiological studies of SLE in northern England or Scotland would be of interest to investigate the effect of higher latitude on the prevalence of SLE.

An important finding, common to the Sweden, Iceland, and United Kingdom studies is the high age specific annual incidence rates in middle age. Systemic lupus erythematosus is typically thought of as a disease of women in their childbearing years, ${ }^{27}$ and early studies from New York did show peak incidence rates in women aged 15-44 years. ${ }^{2}$ In Baltimore, Maryland, however, from 1970 to 1977, the peak incidence rates were in women aged 45-54 years, with a mean age at diagnosis of $41 \cdot 7$ years. ${ }^{28}$ In Sweden, the highest incidence rates were seen in the 55-64 year age group, with the 65-74 year age group next highest. ${ }^{23}$ Similarly, in Iceland, the 50-59 year age group showed the peak age specific annual incidence rate for SLE; the mean age at first symptoms and diagnosis was 37.9 and 46.6 years, respectively. ${ }^{15}$ In the Nottingham study, peak incidence rates were also seen in the 50-59 year age groups (figure) with a median age at diagnosis for women of $47 \cdot 0$ years. ${ }^{18}$ Thus, this higher age at diagnosis seems to be a consistent finding in Europe, though it is not clear whether this represents a true increase in middle age or a relative decrease in presentation in younger subjects.

In summary, SLE may be less common in the United Kingdom than in either Scandinavia or the USA. The reason for these differences is not clear, but probably reflects environmental and genetic influences. An up to date epidemiological study in the USA would be of interest, as would studies on the occurrence of SLE from the north of the UK. In Europe it is clear that SLE is not a disease confined to young women, with peak incidence rates occurring in women of middle age.

1 Hochberg M. Prevalence of systemic lupus erythematosus in England and Wales, 1981-2. Ann Rheum Dis 1987; 46 : $664-6$

2 Siegel $\dot{M}$. Lee S L. The epidemiology of systemic lupus erythematosus. Semin Arthritis Rheum 1973; 3: 1-54.

3 Kurland L, Hauser W, Ferguson R, Holley K. Epidemiologic features of diffuse connective tissue disorders in Rochester, Minn., 1951 through 1967, with special reference systemic lupus erythematosus. Mayo Clin Proc 1969; 44: 649-63.

4 Michet C J, McKenna C H, Elveback L R, Kaslow R A, Kurland $\mathbf{L}$ T. Epidemiology of systemic lupus erythematosus and other connective tissue diseases in Rochester Minnesota, 1950 through 1979. Mayo Clin Proc 1985; 60: 105-13.

5 Tan E, Cohen A, Fries J, et al. The 1982 revised criteria for the classification of systemic lupus erythematosus. Arthritis Rheum 1982; 25: 1271-7.

6 Fessel W J. Systemic lupus erythematosus in the community: incidence, prevalence, outcome and first symptoms; the high prevalence in black women. Arch Intern Med 1974 134: 1027-35.

7 Wilson W, Hughes G. Rheumatic disease in Jamaica. Ann Rheum Dis 1979; 38: 320-5.

8 Greenwood B. Autoimmune disease and parasitic infections in Nigerians. Lancet 1968; ii: $380-2$.

9 Somorin A, Adesugba J. Incidence of lupus erythematosus in Nigeria. F Dermatol 1981; 8: 151-6.

10 Morrison R C A, Gear A J, Kark A, Mevers A, Goldberg B. Differences in systemic lupus erythematosus among 4 racia

11 Frank A. Apparent predisposition to systemic lupus ery- 
thematosus in Chinese patients in West Malaysia. Ann Rheum Dis 1980; 39: 266-9.

12 Feng $\mathbf{P}$, Boey $\mathbf{M}$. Systemic lupus erythematosus in Chinese: the Singapore experience. Rheumatol Int 1982; 2: 151-4. 3 Nai-Cheng C. Rheumatic diseases in China. $f$ Rheumatol Suppl 1983; 10: 41-4.

14 Nived O, Sturfelt G, Wollheim F. Systemic lupus erythematosus in an adult population in southern Sweden: incidence/ prevalence and validity of ARA revised criteria. $\mathrm{Br} \mathcal{F}$ Rheumatol 1985; 24: 147-54.

15 Gudmundsson S, Steinsson K. Systemic lupus erythematosus in Iceland 1975 through 1984. A nationwide epidemiological study in an unselected population. $\mathcal{F}$ Rheumatol $1990 ; 17$ : 1162-7.

16 Samanta A, Feehally J, Roy S, Nichol F E, Sheldon P J, Walls $J$. High prevalence of systemic disease and mortality in Asian subjects with systemic lupus erythematosus. $A n n$ Rheum Dis 1991; 50: 490-2.

17 Samanta A, Roy S, Feehally J, Symmons D. The prevalence of diagnosed systemic lupus erythematosus in whites and Indian Asian immigrants in Leicester City, UK. Lupus Indian Asian immigrants

18 Hopkinson N, Doherty $M$, Powell $R$. The prevalence and incidence of systemic lupus erythematosus, UK, 1989-90. $B r \mathcal{F}$ Rheumatol. In press.

19 Leonhardt T. Family studies in systemic lupus erythematosus. Acta Med Scand 1964; 416 (suppl): 1-156.
20 Estes D, Christian C. The natural history of systemic lupus erythematosus by prospective analysis. Medicine (Baltimore) 1971; 50: 85-95.

21 Lee P, Urowitz M, Bookman A, et al. Systemic lupus erythematosus. A review of 110 cases with reference to nephritis, the nervous system, infections, aseptic necrosis nephritis, the nervous system, infections,

22 Swaak A J G, Nossent J C, Bronsveld W, et al. Systemic lupus erythematosus. I. Outcome and survival: Dutch experience with 110 patients studied prospectively. Ann Rheum Dis 1989; 48: 447-54.

23 Jonsson H, Nived O G S A S. Estimating the incidence of systemic lupus erythematosus in a defined population using multiple sources of retrieval. $\mathrm{Br} \mathcal{F}$ Rheumatol 1990; 29: $185-8$.

24 Hopkinson N, Doherty M, Powell R. Estimating the incidence of SLE [letter]. Br F Rheumatol 1990; 29: 498.

25 Bingley P, Gale E. Rising incidence of IDDM in Europe. Diabetes Care 1989; 12: 289-95.

26 McDonald W. The pathogenesis of multiple sclerosis. The Bradshaw Lecture 1986. F R Coll Physicians Lond 1986; 21 : 287-94.

27 Hughes G. Systemic lupus erythematosus. 6th ed. Edinburgh: Churchill Livingstone, 1986.

28 Hochberg M C. The incidence of systemic lupus erythematosus in Baltimore, Maryland, 1970-1977. Arthritis Rheum 1985; 28: 80-6. 